SPECIAL REPORT

\title{
Homeless Management during Movement Control Order Due to COVID-19 Pandemic: Experience from Federal Territory Kuala Lumpur, Malaysia
}

\author{
Haliza Abdul Manaf ${ }^{1}$, Rozita Arifin ${ }^{1}$ and Mohd Rizal Abdul Manaf ${ }^{*}$ \\ ${ }^{1}$ Cawangan Kesihatan Primer, Jabatan Kesihatan Wilayah Persekutuan Kuala Lumpur dan Putrajaya. \\ ${ }^{2} J a b a t a n$ Kesihatan Masyarakat, Fakulti Perubatan, Universiti Kebangsaan Malaysia.
}

*For reprint and all correspondence: Mohd Rizal Abdul Manaf, Jabatan Kesihatan Masyarakat, Fakulti Perubatan, Universiti Kebangsaan Malaysia.

Email:drmrizal@ukm.edu.my

\section{ABSTRACT}

\begin{abstract}
Malaysia has been hit by COVID-19 pandemic since 2020 and this problem also affects countries around the world. This COVID-19 infection does not distinguish age, gender, educational and financial status. Homeless people are also not exempt from being infected with COVID-19, especially when the government implements the Movement Control Order, particularly these people who have no permanent home. This article describes the activities carried out by the government agencies, especially from the Ministry of Health Malaysia, Department of Social Welfare, National Anti-Drugs Agency, Immigration Department of Malaysia, as well as other non-governmental agencies in the Federal Territory of Kuala Lumpur on homeless people during movement control orders. It is hoped that this shared experience can be a guide to government agencies, non-governmental organizations, private sectors and individuals in other states to manage this underprivileged group, especially during the ongoing COVID-19 pandemic

Keywords COVID-19 - movement control order - homeless - Malaysia.
\end{abstract}

Article history

Received: 28 January 2021

Accepted: 2 August 2021

Published: 1 September 2021 
International Journal of Public Health Research Vol 11 No 2 2021, pp (1480-1485)

\begin{abstract}
ABSTRAK
Malaysia telah dilanda pandemik COVID-19 semenjak tahun 2020 dan masalah ini juga melibatkan negara-negara di seluruh dunia. Infeksi COVID-19 ini tidak mengenal status umur, jantina, tahap pendidikan dan kewangan. Golongan gelandangan juga tidak terkecuali dari dijangkiti COVID-19 ini lebih-lebih lagi apabila kerajaan melaksanakan Perintah Kawalan Pergerakan, terutama golongan ini yang tiada tempat tinggal yang tetap. Artikel ini menerangkan aktiviti-aktiviti yang dijalankan oleh agensi kerajaan, terutama dari Kementerian Kesihatan Malaysia, Jabatan Kebajikan Masyarakat, Agensi Anti-Dadah Kebangsaan dan Jabatan Imigresen Malaysia serta agensi-agensi bukan kerajaan yang lain di Wilayah Persekutuan Kuala Lumpur ke atas golongan gelandangan semasa perintah kawalan pergerakan. Pengalaman yang dikongsi bersama ini diharap dapat menjadi panduan kepada agensi-agensi kerajaan, organisasi bukan kerajaan, pihak swasta dan persendirian di negeri lain untuk menguruskan golongan yang kurang bernasib baik ini terutama sekali semasa pandemik COVID-19 yang masih berlarutan.

Kata Kunci COVID-19, perintah kawalan pergerakan, gelandangan, Malaysia.
\end{abstract}




\section{PENGENALAN}

Wabak penyakit Coronavirus telah mula dikesan di bandar Wuhan, Hubei, China pada Disember 2019 apabila terdapat beberapa kes radang peparu yang tidak diketahui punca atau etiologinya. Pertubuhan Kesihatan Sedunia (World Health Organization, WHO) telah mengisytiharkan wabak COVID-19 sebagai kecemasan kesihatan awam yang membimbangkan di peringkat antarabangsa pada Januari 2020 dan seterusnya mewartakan sebagai pandemik global pada 17 Mac 2020. ${ }^{1}$

Malaysia telah dilanda penyakit COVID19 apabila pelancong Malaysia balik dari China pada 20 Januari 2020 dan telah merebak ke beberapa tempat. $^{2}$ Wabak COVID-19 meletus selepas perhimpunan agama besar-besaran di Kuala Lumpur, di mana seramai 637 dari lebih 16,000 peserta didapati positif. Berikutan dari bilangan kes yang dikaitkan dengan perhimpunan tersebut, kerajaan Malaysia telah mengambil keputusan mengimplementasi Perintah Kawalan Pergerakan (PKP) di seluruh negara pada 18 Mac 2020, berdasarkan Akta Pencegahan dan Pengawalan Penyakit Berjangkit $1988 .^{2}$ Orang ramai digesa melaksanakan penjarakan sosial, mengelakkan perhimpunan, memakai pelitup mula dan kerap mencuci tangan.

Pengawalan Jangkitan COVID-19 Dalam Kalangan Gelandangan

Dalam menjalankan aktiviti pencegahan dan pengawalan jangkitan COVID-19 di Wilayah Persekutuan Kuala Lumpur (WPKL), terdapat masalah untuk memberi perlindungan kepada golongan yang tidak mempunyai tempat tinggal yang tetap. Berkaitan dengan isu ini, pada 28 Mac 2020, Kementerian Wilayah Persekutuan telah mencapai keputusan bagi menyediakan penempatan sementara kepada golongan gelandangan ini (warganegara dan bukan warganegara). Dewan Bandaraya Kuala Lumpur (DBKL) telah diarahkan untuk meneraju inisiatif program penempatan bagi golongan gelandangan ini di penempatan berpusat.

Objektif utama inisiatif ini adalah bagi membendung penularan wabak COVID-19 dari golongan gelandangan kepada masyarakat sekeliling dan juga sebaliknya. Penempatan bagi golongan gelandangan di pusat sementara adalah untuk memudahkan pengawasan dan pemerhatian yang menyeluruh, menjalankan pemeriksaan kesihatan asas, penyaringan COVID-19 dan bagi memastikan mereka selamat sehingga PKP tamat. Usaha bagi menyelamatkan golongan gelandangan ini melibatkan pelbagai agensi kerajaan dan juga bukan kerajaan yang termasuk aktiviti penempatan sementara (Ops Gelandangan) dan pemeriksaan kesihatan.

Ops Gelandangan ini merupakan suatu operasi yang dijalankan bagi menyelamatkan golongan gelandangan dengan mengumpulkan mereka dalam pusat jagaan sementara. Ia dilaksanakan di beberapa lokasi termasuk Masjid Negara, sekitar Kotaraya, Pasar Seni, KL Sentral, Masjid Jamek, Dataran Merdeka dan tempat-tempat lain. Pusat-pusat komuniti, dewan serbaguna dan kompleks sukan yang sesuai dijadikan tempat penempatan sementara bagi gelandangan telah dikenalpasti. Pada 29 Mac 2020, Pusat Komuniti Sentul Perdana telah mula beroperasi dengan menerima 179 gelandangan, diikuti pembukaan beberapa Pusat Sementara Gelandangan (PSG) berdasarkan keperluan semasa.

Pusat penempatan sementara ini dilengkapi dengan kemudahan tempat tidur, keperluan asas, menyediakan makanan dan minuman yang mencukupi serta kubikel tersendiri. Setelah beberapa Ops Gelandangan dijalankan, penempatan sementara gelandangan telah meningkat kepada 12 buah pusat. Seramai 923 orang gelandangan telah menerima perkhidmatan ini di seluruh Kuala Lumpur di penempatan sementara seperti yang disenaraikan dalam Jadual 1, selain dari Pusat Transit Gelandangan di Jalan Pahang dan Anjung Singgah di Jalan Hang Lekiu yang mana pusat-pusat ini telah sedia ada wujud sebelum PKP dilaksanakan. Dari jumlah seramai 923 orang ini, sebanyak $92.3 \%$ (852 orang) adalah warganegara Malaysia, manakala $7.7 \%$ atau 71 orang terdiri dari penghuni yang bukan warganegara.

Penempatan sementara ini dikategorikan mengikut jantina, warganegara atau bukan warganegara, sihat atau tidak sihat (mempunyai penyakit berjangkit, mengalami penyakit mental dan menghadapi masalah penyalahgunaan dadah). Pembahagian ini memudahkan agensi-agensi pelaksana bagi menguruskan golongan gelandangan ini secara lebih sistematik dan efisien. 

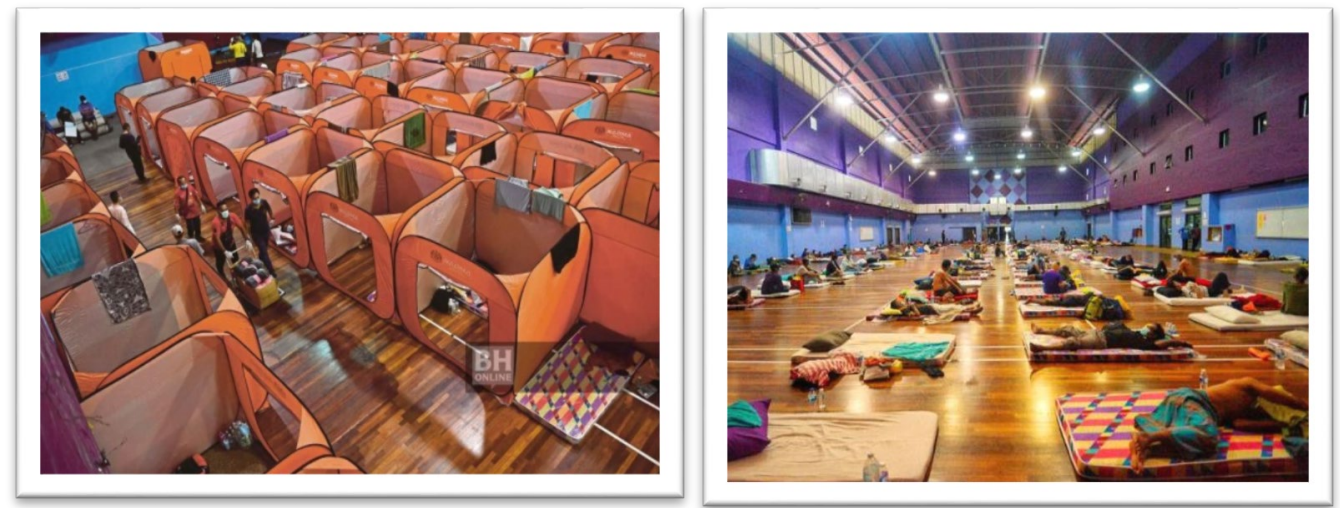

Gambarajah 1 dan 2 Sebelum dan selepas pemasangan kubikel di Pusat Komuniti Sentul Perdana.
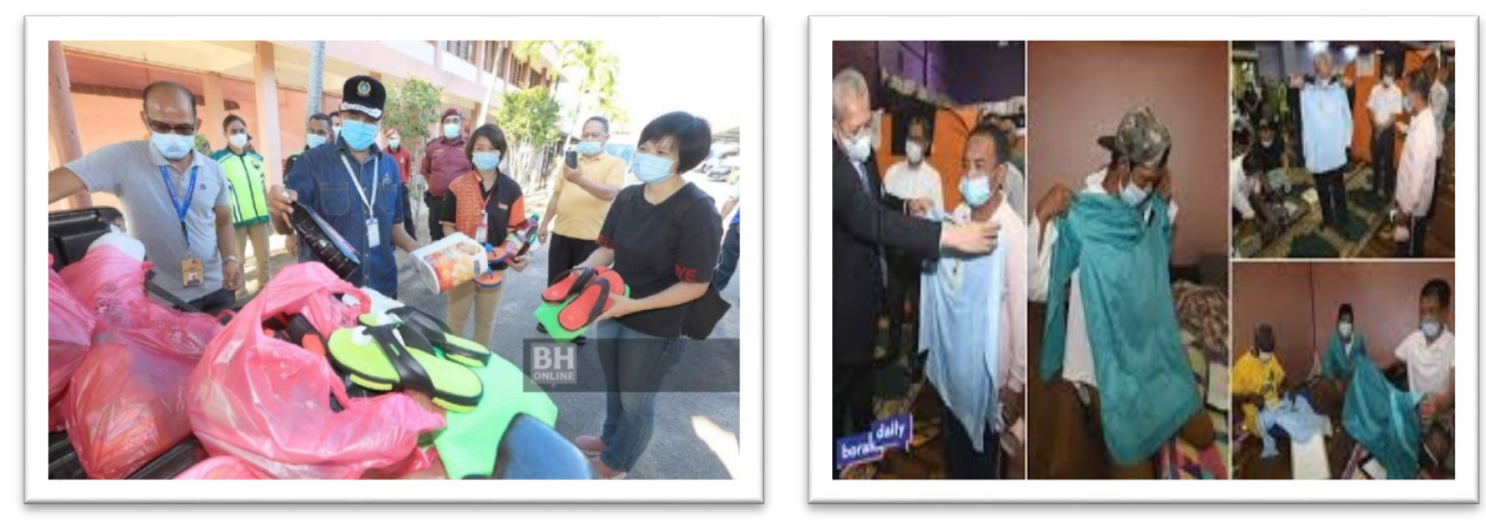

Gambar 3 dan 4 Sumbangan dari pelbagai agensi kerajaan dan bukan kerajaan, termasuk dari orang perseorangan.

Jadual 1 Senarai Pusat Sementara Gelandangan semasa PKP

\begin{tabular}{clr}
\hline $\begin{array}{c}\text { Pejabat kesihatan } \\
\text { daerah }\end{array}$ & \multicolumn{1}{c}{ Pusat sementara gelandangan } & $\begin{array}{c}\text { Jumlah } \\
\text { gelandangan }\end{array}$ \\
\hline TITIWANGSA & $\begin{array}{l}\text { DEWAN SERBAGUNA AMPANG HILIR. } \\
\text { Jln Kedondong, Desa Pahlawan, 55000, KL }\end{array}$ & 120 \\
& PUSAT TRANSIT GELANDANGAN & 83 \\
& KUALA KUMPUR. 20, Jalan Pahang, \\
& Titiwangsa Sentral, 53000 KL. \\
& PUSAT KOMUNITI SETIAWANGSA. & 132 \\
& AU2, 54200, KL. & \\
& DEWAN SERBAGUNA MELATI & \\
& IMPIAN. & \\
& Jalan Madrasah, Gombak Setia, KL & \\
KEPONG & PUSAT KOMUNITI SENTUL PERDANA. & \\
& Jln 2/48A, Bandar Baru Sentul, 51000, KL. \\
& KOMPLEKS SUKAN SERI DELIMA. & \\
& Lot 965, Kampung Seri Delima, Jalan & \\
& Kuching Pekan, 52000, KL. & \\
& PUSAT KOMUNITI BUKIT & \\
& DAMANSARA. \\
& No 3, Jalan, Pinggiran Setiabudi, Bukit & \\
DEMBAH & Damansara, 50490 KL & \\
PANTAI & No 28-32, Bangunan Ehsan, Jalan Hang & \\
& Lekiu, KL &
\end{tabular}


PT 80

Lorong Bunus 4, City Centre, $50100 \mathrm{KL}$

PUSAT KOMUNITI BUKIT

BANDARAYA.

Jalan Medang Tanduk, Bukit Bandaraya, $59100 \mathrm{KL}$.

CHERAS KOMPLEKS SUKAN DBKL DESA

TASIK.

Jln 20C/146, Taman Desa Tasek, 57000,

Kuala Lumpur

DEWAN SERBAGUNA ALAM DAMAI.

Jalan Damai Puspa 5, Kuala Lumpur, 56000

Cheras

Jumlah

keseluruhan

Sebelum golongan gelandangan ini ditempatkan dalam pusat sementara, mereka dikehendaki menjalani saringan kesihatan umum dan saringan COVID-19 oleh Kementerian Kesihatan Malaysia (KKM) dengan bantuan Dewan Bandaraya Kuala Lumpur (DBKL) dan Persatuan Bulan Sabit Malaysia (PBSM).

KKM menyaring semua gelandangan dan mengambil sampel COVID-19 sebanyak dua kali, semasa kemasukan ke dalam pusat sementara dan pada hari ke 13 selepas tarikh kemasukan. Saringan pertama dijalankan menggunakan ujian swab nasofarinks/ orofarinks dan dihantar ke makmal yang diiktiraf KKM (ujian RT-PCR). Saringan kedua menggunakan ujian RTK-Ab yang dijalankan di pusat sementara gelandangan.

Dari lebih 900 gelandangan yang disaring, terdapat tiga orang $(0.3 \%)$ didapati positif dan telah dirawat dengan sempurna mengikut garispanduan KKM di hospital COVID-19.
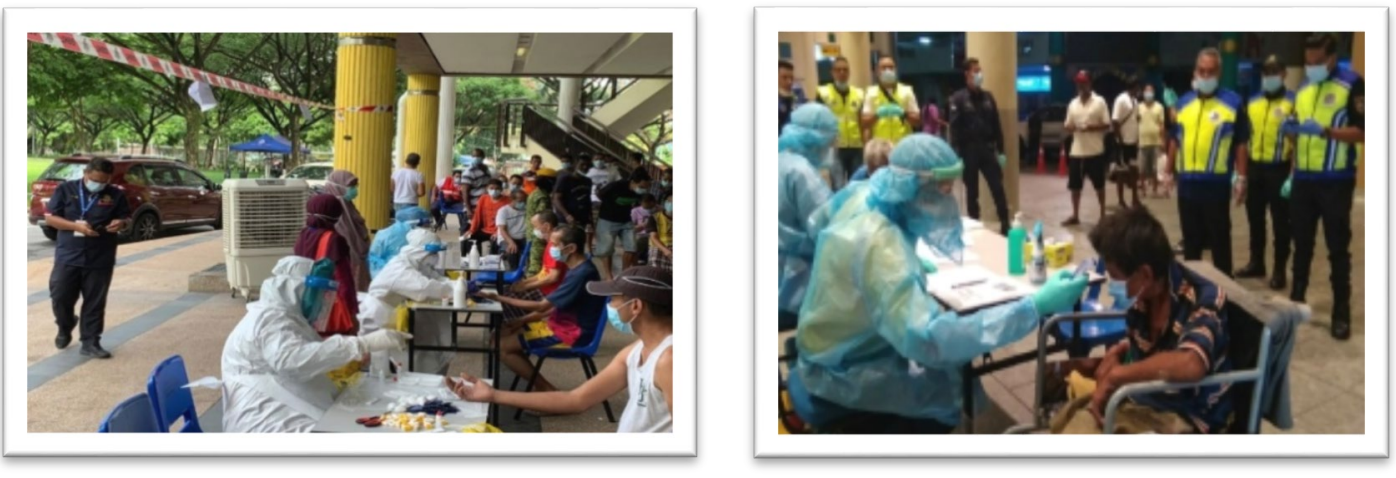

Gambar 5 dan 6 Saringan COVID-19 dan pemeriksaan kesihatan kepada penghuni pusat sementara gelandangan.

KKM telah memastikan maklumat mengenai COVID-19 dari segi kesan dan langkahlangkah pengawalan ditekankan dan disampaikan dengan menyeluruh kepada kakitangan dan penghuni pusat gelandangan termasuk aspek kebersihan diri, etika pernafasan/batuk, penjarakan sosial, (sekurang-kurangnya satu meter), sering mencuci tangan, pemakaian pelitup muka dan amalan pembasmian kuman. ${ }^{3}$ Bagi memastikan prosedur operasi standard (SOP) yang disarankan oleh KKM dilaksanakan dan dipatuhi dalam pusat sementara gelandangan, pemantauan dan perjumpaan berkala dijalankan oleh pegawaipegawai KKM bersama dengan agensi-agensi lain. 

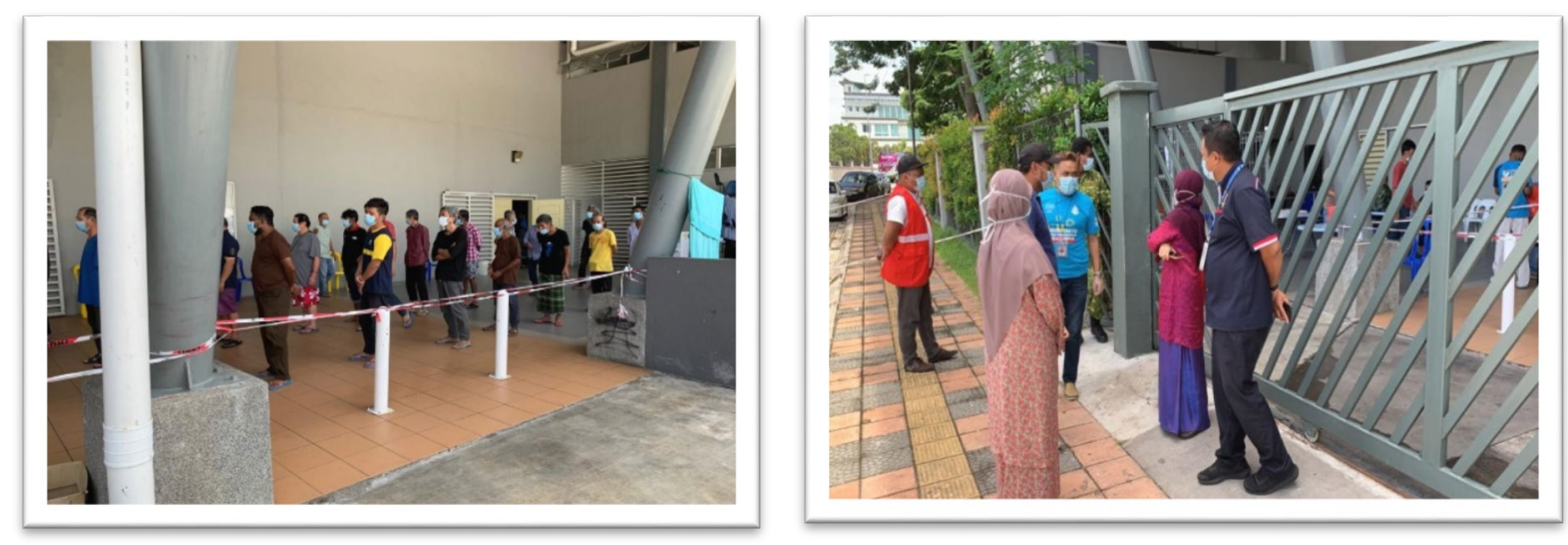

Gambar 7 dan 8 Pemantauan dan pemeriksaan prosedur operasi standard oleh pegawai-pegawai KKM dan agensi-agensi lain.

Penghuni pusat sementara gelandangan juga diberi rawatan perubatan asas bagi penyakitpenyakit akut dan kronik termasuk penjagaan luka (pencucian luka). Gelandangan yang mengidap masalah psikiatri telah dirawat oleh pakar perubatan dari KKM dan akan dirujuk bagi kemasukan ke wad sekiranya masalah tersebut tidak dapat dirawat di pusat sementara gelandangan. Bagi mereka yang mengalami masalah psikiatri ringan, kaunseling dan terapi psikologi diberikan oleh kaunselor-kaunselor dari Jabatan Kebajikan Masyarakat. Terdapat juga bekas penagih dadah dan sedang mendapatkan terapi penggantian metadon, juga mereka dibekalkan rawatan metadon oleh kakitangan KKM di pusat ini.

Kerajaan Malaysia telah bersetuju memberi pengecualian kepada bayaran rawatan untuk semua penghuni pusat sementara gelandangan (warganegara dan bukan warganegara) semasa PKP akibat pandemik COVID-19. Wawasan kerajaan adalah untuk memastikan golongan gelandangan terutama sekali warganegara Malaysia boleh bekerja dan berdikari bagi menyara kehidupan mereka hingga berupaya memperolehi tempat tinggal yang tetap dan tidak lagi bergantung kepada belas ihsan orang ramai.

Beberapa strategi telah dirancang bagi mengatur hala tuju golongan gelandangan ini selepas PKP. Kementerian Wilayah Persekutuan telah memperuntukkan dana khas untuk menjaga kebajikan golongan gelandangan ini di ibu negara. Kementerian Wilayah Persekutuan juga memulakan program penyediaan kerjaya dan penempatan pekerjaan dengan kerjasama dari agensi kerajaan dan bukan kerajaan. Bagi gelandangan yang memiliki sejarah hitam sebelum ini seperti terlibat dengan penyalahgunaan dadah dan lain-lain kesalahan, mereka dihantar menghadiri kursuskursus motivasi, pemulihan akhlak, nasihat kerjaya sebelum memulakan pekerjaan mereka.

Bagi golongan gelandangan yang tidak sihat, mengalami penyakit serius, warga emas dan mempunyai kecacatan, mereka diserahkan kepada Jabatan Kebajikan Masyarakat. Penagih dadah yang kronik telah dirujuk kepada Agensi Anti-Dadah Kebangsaan, manakala pendatang asing tanpa izin diserahkan kepada Jabatan Imigresen Malaysia untuk tindakan lanjut. Usaha-usaha bagi mengatur strategi dan inisiatif untuk menyelamatkan gelandangan sama ada warganegara atau bukan warganegara ditanggung sepenuhnya oleh Kerajaan Malaysia tanpa sebarang bayaran dikenakan.

\section{KESIMPULAN}

Pengurusan golongan gelandangan semasa perintah kawalan pergerakan akibat pandemik COVID-19 oleh kerajaan Malaysia amatlah baik dan tersusun. Diharap segala pengalaman yang dikongsi bersama ini dapat menjadi panduan kepada agensi-agensi kerajaan, organisasi bukan kerajaan, pihak swasta dan persendirian di negeri lain untuk menguruskan golongan yang kurang bernasib baik ini terutama sekali semasa pandemik COVID-19 yang masih berlanjutan.

\section{RUJUKAN}

1. World Health Organization (WHO). 2020. Novel Coronavirus (2019-Ncov) Situation Report-3 $23 \quad$ January 2020. https://apps.who.int/iris/bitstream/handle/1 0665/330762/ nCoVsitrep23Jan2020 eng.pdf.

2. Elengoe, A. 2020. Covid-19 Outbreak in Malaysia. Osong public health and research perspectives 11(3): 93-100.

3. KKM. 2020. Terma Rujukan Bagi Petugas Kesihatan Di Pusat Sementara Gelandangan (PSG) Di Kuala Lumpur Dan Putrajaya. 